\title{
IMAJU LI HRVATSKA DJECA UREDNOG RAZVOJA UISTINU „UREDNU“ KOMUNIKACIJU?
}

\author{
KRISTINA KLJUNIĆ, MAJA CEPANEC, SANJA ŠIMLEŠA \\ Laboratorij za istraživanje dječje komunikacije, Odsjek za logopediju, Edukacijsko-rehabilitacijski fakultet, \\ Borongajska cesta 83f, 10000 Zagreb
}

Primljeno: 2.5.2016.

Izvorni znanstveni rad

Prihvaćeno: 15.7.2016.

UDK: $159.922 .7: 808.56$

Sažetak: Obilježja verbalne komunikacije, neverbalne komunikacije i pragmatike u velikoj su mjeri određena kulturom $i$ socijalnim očekivanjima pojedinog društva. Procjena komunikacijskih obilježja važna je u dijagnostici brojnih razvojnih poremećaja, posebice poremećaja iz spektra autizma, te se u posljednje vrijeme sve više ističe potreba kulturnog prilagođavanja ljestvica za probir i dijagnostiku poremećaja iz spektra autizma.

Cilj ovog rada bio je ispitati obilježja verbalne komunikacije, neverbalne komunikacije i pragmatike hrvatske djece predškolske dobi (petogodišnjaka i šestogodišnjaka) urednog razvoja, te ih sagledati i kodirati na način kako to čini Opservacijski protokol za dijagnostiku poremećaja iz spektra autizma Autism Diagnostic Observation Schedule (ADOS-2; modul 3).

Rezultati su pokazali da hrvatska djeca pokazuju uglavnom očekivana obilježja verbalne komunikacije (obilježja jezične proizvodnje i govora), no da pokazuju različitosti od očekivanih ponašanja u neverbalnoj komunikaciji, $i$, u znatnoj mjeri, obilježjima pragmatike. Razlike su najviše uočene u količini spontane uporabe gesta i svim varijablama pragmatike koje u obzir uzimaju količinu inicijative u komunikaciji (primjerice, spontano traženje ili davanje informacija). Primjerice, samo 15\% djece u uzorku je tražilo informacije onom učestalošću koja se procjenjuje ,, urednom“ prema kodovima protokola ADOS-2.

Premda su među djecom uočene znatne individualne razlike, količina „odstupajućih“ ponašanja u obilježjima neverbalne komunikacije i pragmatike navodi na potrebu preispitivanja zadanih kodova i prilagođavanja kriterija različitim kulturama.

Ključne riječi: verbalna komunikacija, neverbalna komunikacija, pragmatika, djeca predškolske dobi, ADOS-2

\section{UVOD}

Kada se analiziraju obilježja komunikacije, u literaturi se najčešće spominje podjela na verbalnu i neverbalnu komunikaciju. Neverbalna komunikacija uključuje niz ponašanja - uporabu pogleda, izraze lica, posturu tijela, fizičku udaljenost od komunikacijskog partnera i sl. Verbalna komunikacija odnosi se na uporabu jezika, koji može biti govoreni, pisani, ostvaren putem znakovnog jezika i sl.. Također, obilježja komunikacije ovise i o pragmatici, odnosno načinu uporabe jezika.

Procjena komunikacijskih obilježja važna je u dijagnostici brojnih razvojnih poremećaja, posebice poremećaja iz spektra autizma (PSA). Prema trenutno važećoj Međunarodnoj klasifikaciji bolesti (MKB-10; Svjetska zdravstvena organizacija,
1994) i Dijagnostičkom i statističkom priručniku za duševne poremećaje (DSM-5; Američka psihijatrijska udruga, 2014), glavninu dijagnostičkih kriterija za poremećaj iz spektra autizma čine oni koji se odnose na obilježja komunikacije.

No, upravo činjenica da su gotovo svi međunarodno priznati mjerni instrumenti za probir i dijagnostiku poremećaja iz spektra autizma razvijeni u Sjedinjenim Američkim Državama dovodi u pitanje njihovu kulturalnu prilagođenost različitim populacijama i naglašava potrebu preispitivanja određenih dijagnostičkih normi i kriterija. Naime, poznato je da su obilježja i verbalne i neverbalne komunikacije prilično određena kulturalnim normama (za detaljni pregled vidi McLaren, 1998). Primjerice, učestalost uspostave kontakta očima, kao i dužina njegovog trajanja se razlikuje od kulture do kulture. U zapad- 
nim kulturama produženi kontakt očima može ukazivati na iskrenost i pristupačnost, dok se u Aziji može interpretirati kao upadno ili nepristojno ponašanje - tako u Japanu i Kini djecu podučavaju da u komunikaciji s odraslima ne uspostavljaju direktan kontakt očima, kao znak pristojnosti i poštovanja (Moran i sur., 2007; Zhang i sur., 2006).

Osim u kontaktu očima (Akechi i sur., 2013), kulturalne razlike zabilježene su i u izrazima lica (Jack, Garrod i sur., 2012), pragmatici (DeZarobe i DeZarobe, 2012), uporabi gesta (Huttunen i sur., 2013) i sl.

Čak i u samoj populaciji djece s poremećajem iz spektra autizma, kulturalne razlike uočene su ne samo u obilježjima verbalne i neverbalne komunikacije, već i u obilježjima repetitivnog ponašanja (Magaña i Smith, 2013) i senzoričke obrade (Al-Heizan i sur., 2015; Caron i sur., 2012), koja također čine dijagnostičke kriterije poremećaja iz spektra autizma.

Iz tih razloga se u posljednje vrijeme sve više ističe potreba kulturalnog prilagođavanja, kako ljestvica za probir poremećaja iz spektra autizma (za pregled vidi Soto i sur., 2014), tako i cjelokupnog dijagnostičkog postupka i dijagnostičkih kriterija (DeWeerdt, 2012; Ennis-Cole i sur., 2013; Matson i sur., 2011; Norbury i Sparks, 2013; Perepa, 2014; Zhang i sur., 2006). Naime, procjena obilježja specifičnih ponašanja koja se ispituju unutar dijagnostičkog protokola uključuje odluku radi li se o značajno odstupajućem ponašanju ili ponašanju koje se nalazi u zoni individualnih razlika unutar tipičnog obrasca razvoja. Ta odluka je u velikoj mjeri arbitrarna i pod utjecajem kulturnih normi i očekivanja samog ispitivača. U prilog navedenoj tezi govore i izvještaji roditelja djece s poremećajem iz spektra autizma - tako, primjerice, roditelji koji žive u istoj državi, ali pripadaju razlčitim etničkim skupinama, pridaju različitu važnost različitim socijalnim vještinama i različito ih ocjenjuju (Perepa, 2014). I premda se možemo složiti da, sveukupno, dijagnostički kriteriji uključeni u algoritam dijagnostike poremećaja iz spektra autizma ugrubo doista razlikuju djecu $\mathrm{s}$ poremećajem iz spektra aurtizma od djece urednog razvoja, normativni razvojni podaci o pojedinačnim ponašanjima koja su uključena u algoritam su, vrlo vjerojatno, različiti u različitim kulturama.

Premda i Hrvatska i SAD pripadaju zapadnoj kulturi, otvara se pitanje individualnih razlika $i$ granice individualnih razlika i odstupanja u pojedinim aspektima verbalne i neverbalne komunikacije, posebice u djece predškolske dobi. Primjerice, sve donedavno se u Hrvatskoj djecu učilo da je nepristojno pokazivati prstom (obilježje neverbalne komunikacije koje se ispituje u dijagnostičkom protokolu ADOS-2), kao i da nije pristojno niti uputno nepoznatoj odrasloj osobi postavljati osobna pitanja ili iznositi vlastite misli i osjećaje (obilježja pragmatike koja se ispituju u dijagnostičkom protokolu ADOS-2).

\section{CILJ}

Cilj je ovog rada ispitati obilježja verbalne i neverbalne komunikacije hrvatske djece predškolske dobi urednog razvoja, te ih sagledati na način kako to čini Opservacijski protokol za dijagnostiku autizma Autism Diagnostic Observation Schedule (ADOS-2; Lord i sur., 2012) koja se globalno u svijetu koristi u postupku dijagnostike poremećaja iz spektra autizma i koja čini ,zlatni standard" u dijagnostici PSA-a. Jednako tako, cilj je i sagledati pokazuju li hrvatski predškolci razlike u „uspješnosti“ na varijablama verbalne i neverbalne komunikacije i pragmatike, odnosno odstupaju li od čekivanog (onako kako to definira protokol ADOS-2) više u obilježjima verbalne, neverbalne komunikacije ili pragmatike.

\section{METODE RADA}

\section{Uzorak sudionika}

Ispitivanjem je obuhvaćeno 60 -ero djece (30 dječaka i 30 djevojčica) dobi 5.0-6.5 godina (tablica 1). Sudionici istraživanja su djeca koja pohađaju redovne vrtićke skupine u zagrebačkim vrtićima. Djeca su odabrana na temelju kriterija urednog

Tablica 1. Opis ispitanika.

\begin{tabular}{|c|c|c|c|}
\hline & $\mathbf{N}$ & $\%$ \\
\hline \multirow[t]{2}{*}{ Spol } & Dječaci & 30 & 50 \\
\hline & Djevojčice & 30 & 50 \\
\hline & & M & SD \\
\hline \multicolumn{2}{|c|}{ Kronološka dob (godine) } & 5,9 & 0,5 \\
\hline \multicolumn{2}{|c|}{ Dob kad je dijete prohodalo (mjeseci) } & 12,1 & 2,9 \\
\hline \multicolumn{2}{|c|}{ Dob pojave prve riječ (mjeseci) } & 10,3 & 6,6 \\
\hline \multicolumn{2}{|c|}{ Dob polaska u vrtić (mjeseci) } & 22,3 & 9,6 \\
\hline
\end{tabular}


Tablica 2. Naziv i opis varijabli.

\begin{tabular}{|c|c|c|}
\hline Grupna varijabla & Naziv pojedine varijable & Kratki opis \\
\hline \multirow{4}{*}{$\begin{array}{l}\text { Verbalna } \\
\text { komunikacija }\end{array}$} & Ukupna razina neeholaličnog govornog jezika & Procjenjuje se složenost i kvaliteta jezične proizvodnje \\
\hline & Neobičnosti u obilježjima govora & $\begin{array}{l}\text { Procjenjuje se postojanje odstupanja u intonaciji, } \\
\text { glasnoći, ritmu ili brzini govora }\end{array}$ \\
\hline & Neposredna eholalija & Procjenjuje se učestalost prisutnosti eholalije \\
\hline & $\begin{array}{l}\text { Stereotipna/idiosinkratska uporaba riječi ili } \\
\text { fraza }\end{array}$ & $\begin{array}{l}\text { Procjenjuje se fleksibilnost i neobičnosti jezične } \\
\text { proizvodnje }\end{array}$ \\
\hline \multirow[t]{4}{*}{ Pragmatika } & Davanje novih informacija & $\begin{array}{l}\text { Procjenjuje se koliko često dijete spontano daje osobne } \\
\text { informacije ispitivaču }\end{array}$ \\
\hline & Traženje informacija & $\begin{array}{l}\text { Procjenjuje se koliko često dijete pokazuje interes za } \\
\text { ideje, iskustva ili reakcije ispitivača }\end{array}$ \\
\hline & Opisivanje događaja & $\begin{array}{l}\text { Procjenjuje se koliko jasno dijete može na razumljiv } \\
\text { način opisati poznati događaj i pritom odabrati optimalne } \\
\text { informacije }\end{array}$ \\
\hline & Razgovor & $\begin{array}{l}\text { Procjenjuje se kvaliteta razgovora, recipročnost i } \\
\text { nadovezivanje u razgovoru }\end{array}$ \\
\hline \multirow[t]{4}{*}{$\begin{array}{l}\text { Neverbalna } \\
\text { komunikacija }\end{array}$} & $\begin{array}{l}\text { Opisne, konvencionalne, instrumentalne ili } \\
\text { informativne geste }\end{array}$ & Procjenjuje se učestalost spontane uporabe gesta \\
\hline & Kontakt očima & $\begin{array}{l}\text { Procjenjuje se koliko je kontakt očima jasan, fleksibilan, } \\
\text { socijalno usklađen i primjeren komunikaciji }\end{array}$ \\
\hline & Izrazi lica & $\begin{array}{l}\text { Procjenjuje se koliko često dijete upućuje izraze lica } \\
\text { ispitivaču u svrhu komuniciranja emocionalnih stanja }\end{array}$ \\
\hline & Dijeljenje zadovoljstva u interakciji & $\begin{array}{l}\text { Procjenjuje se u kojoj mjeri dijete svjesno pokazuje } \\
\text { ispitivaču zadovoljstvo interakcijom }\end{array}$ \\
\hline $\begin{array}{l}\text { Koordinacija } \\
\text { verbalne i } \\
\text { neverbalne } \\
\text { komunikacije }\end{array}$ & $\begin{array}{l}\text { Jezična proizvodnja i povezana neverbalna } \\
\text { komunikacija }\end{array}$ & $\begin{array}{l}\text { Procjenjuje se stupanj do kojeg dijete, kada komunicira } \\
\text { govorom, prati verbalnu komunikaciju promjenama u } \\
\text { neverbalnoj komunikaciji (pogled, izraz lica, geste). }\end{array}$ \\
\hline
\end{tabular}

komunikacijskog i jezičnog razvoja i pisanog pristanka roditelja.

\section{Mjerni instrument}

Za potrebe istraživanja korišten je protokol Autism Diagnostic Observation Schedule-2 (ADOS-2; Lord i sur., 2012) koji je namijenjen za procjenu komunikacije, socijalne interakcije, igre i suženog i repetitivnog ponašanja, te koji se provodi u djece i osoba u kojih postoji sumnja na poremećaj iz spektra autizma. Protokol se provodi na način da se stvaraju unaprijed zadane polustrukturirane situacije (primjerice, zajedničko čitanje slikovnice), te se kodira opće ponašanje djeteta (primjerice, postavlja li dijete pitanja, koliko pogledava komunikacijskog partnera, dijeli li zadovoljstvo u interakciji i sl.).

\section{Provedba istraživanja}

Ispitivanje se provodilo u prostorima dječjih vrtića, u manjoj zasebnoj prostoriji i trajalo je
30-45 minuta. U provedbi ispitivanja sudjelovala su dva ispitivača. Jedna osoba je ispitivala dijete, dok je druga osoba bilježila reakcije i ponašanja.

Nakon ispitivanja uslijedilo je kodiranje odabranih ponašanja u domenama verbalne komunikacije, neverbalne komunikacije i pragmatike. Svakom ponašanju je dodijeljen kod 0,1 ili 2 na način da 0 označava potpuno uredno funkcioniranje, a kodovi 1 i 2 ukazuju na blaže (kôd 1) ili teže (kôd 2) odstupanje. Kodiranje je obavljeno prema unaprijed definiranim kodovima protokola ADOS-2. Kodiranje je obavljao jedan trenirani ispitivač. Za petero sudionika kodirana su ponašanja od strane dva ispitivača, te je uočena visoka povezanost $(\mathrm{rho}=, 90)$.

Analiza podataka temeljila se na tri glavne skupine varijabli: obilježjima verbalne komunikacije (jezična proizvodnja i govor), obilježjima pragmatike i obilježjima neverbalne komunikacije (vidi tablicu 2). 


\section{REZULTATI I RASPRAVA}

\section{Obilježja verbalne komunikacije}

Pregledom osnovnih statističkih parametara i frekvencije raspodjele rezultata na varijablama verbalne komunikacije (obilježja jezične proizvodnje i govora), sveukupno se može zaključiti da su djeca postigla očekivane rezultate. Niti jedno dijete nije niti na jednoj varijabli jezične proizvodnje i govora ostvarilo kod 2 koji označava odstupajuće ponašanje. Sva djeca pokazala su uredan rezultat (kod 0) na varijablama koje ispituju postojanje neposredne eholalije i fleksibilnosti jezične proizvodnje, tj. neposredna eholalija i stereotipna/idiosinkratska uporaba riječi ili fraza nije pronađena u odstupajućoj mjeri u ovom uzorku djece. U samo dvoje djece uočene su neobičnosti u obilježjima govora (intonaciji, glasnoći, ritmu ili brzini), a najviše odstupanja uočeno je u složenosti jezične proizvodnje. No, sveukupno, većina djece $(80 \%)$ i na toj varijabli pokazuje uredan rezultat (vidi tablicu 3). Uzmemo li u obzir da se radi o petogodišnjacima i šestogodišnjacima, to je i očekivani rezultat budući da djeca u toj dobi i dalje usvajaju i razvijaju svoje jezične vještine te im se potkradaju gramatičke pogreške. Jednako tako, na razini populacije, normalno je očekivati da $10-20 \%$ djece pokazuje nešto nižu složenost i kvalitetu jezične proizvodnje.
Razlike među djecom u toj dobi u obilježjima jezične proizvodnje očekivane su i normalna su pojava jer se jezične vještine još intenzivno razvijaju u predškolskoj dobi, posebice u flektivnim jezicima kao što je hrvatski (za pregled vidi Kuvač Kraljević i Kologranić Belić, 2015). Ono što je uočljivo su visoke vrijednosti standardnih devijacija na varijablama, čak veće od aritmetičkih sredina, što nam ukazuje na postojanje varijacija među djecom u govoru i jeziku. Bates i suradnici (1995) izvještavaju upravo o velikim individualnim razlikama između djece tijekom ranog perioda usvajanja jezika i napominju da te razlike postoje $\mathrm{u}$ gotovo svim aspektima jezičnog razvoja kod djece urednog razvoja kao i kod djece s teškoćama.

\section{Obilježja neverbalne komunikacije}

Na varijablama koje ispituju obilježja neverbalne komunikacije (uporaba gesta, kontakta očima i izraza lica, te dijeljenje zadovoljstva u interakciji) sudionici su pokazali visoki udio očekivanih rezultata u uporabi kontakta očima $(98 \%$ djece postiglo je kod 0) te izraza lica ( $85 \%$ djece postiglo je kod 0 ), no odstupanja se u većoj mjeri uočavaju u dijeljenju zadovoljstva u interakciji i, u izrazito velikoj mjeri, u spontanoj uporabi gesta.

Iz tablice 4 vidljivo je da su djeca u korištenju gesti pokazala velike različitosti i odstupanja od

Tablica 3. Frekvencija i postotak raspodjele rezultata na varijablama verbalne komunikacije (obilježja jezične proizvodnje i govora).

\begin{tabular}{|c|c|c|c|c|c|c|c|c|}
\hline \multirow[t]{3}{*}{ Naziv varijable } & \multicolumn{6}{|c|}{ Kodovi } & \multirow[t]{3}{*}{$\mathbf{M}$} & \multirow[t]{3}{*}{ SD } \\
\hline & \multicolumn{3}{|c|}{$\mathbf{N}$} & \multicolumn{3}{|c|}{ Postotak (\%) } & & \\
\hline & $\mathbf{0}$ & 1 & 2 & $\mathbf{0}$ & 1 & 2 & & \\
\hline Ukupna razina neeholaličnog govornog jezika & 48 & 12 & 0 & 80 & 20 & 0 & 0,20 & 0,40 \\
\hline Abnormalnosti govora povezane s autizmom & 58 & 2 & 0 & 97 & 3 & 0 & 0,03 & 0,18 \\
\hline Neposredna eholalija & 60 & 0 & 0 & 100 & 0 & 0 & 0,00 & $\overline{0,00}$ \\
\hline Stereotipna/idiosinkratska uporaba riječi ili fraza & 60 & 0 & 0 & 100 & 0 & 0 & 0,00 & 0,00 \\
\hline
\end{tabular}

Tablica 4. Frekvencija i postotak raspodjele rezultata na varijablama koje opisuju neverbalnu komunikaciju.

\begin{tabular}{|l|c|c|c|c|c|c|c|c|}
\hline \multirow{2}{*}{ Naziv varijable } & \multicolumn{9}{|c|}{ Kodovi } & \multirow{2}{*}{ M } & \multirow{2}{*}{ SD } \\
\cline { 2 - 8 } & \multicolumn{4}{|c|}{$\mathbf{N}$} & \multicolumn{3}{|c|}{ Postotak (\%) } & \\
\cline { 2 - 8 } & $\mathbf{0}$ & $\mathbf{1}$ & $\mathbf{2}$ & $\mathbf{0}$ & $\mathbf{1}$ & $\mathbf{2}$ & & \\
\hline $\begin{array}{l}\text { Opisne, konvencionalne, instrumentalne ili informativne } \\
\text { geste }\end{array}$ & 20 & 29 & 11 & 33,3 & 48,3 & 18,3 & 0,85 & 0,71 \\
\hline Kontakt očima & 59 & 0 & 1 & 98,3 & 0,0 & 1,7 & 0,03 & 0,26 \\
\hline Izrazi lica & 51 & 8 & 1 & 85,0 & 13,3 & 1,7 & 0,17 & 0,42 \\
\hline Dijeljenje zadovoljstva u interakciji & 42 & 17 & 1 & 70,0 & 28,3 & 1,7 & 0,32 & 0,50 \\
\hline
\end{tabular}


očekivanja. Najveći postotak djece (48,3\%) na ovoj varijabli postigao je kod 1, što znači da najveći broj djece koristi opisne geste (primjerice, pokretima ruke pokazuju kako se četkaju zubi) samo onda kada se to od njih traži, nešto manji postotak djece $(33,3 \%)$ postigao je rezultat 0 što znači da su spontano koristila nekoliko opisnih gesti u svrhu komunikacije, dok je najmanji postotak djece $(18,3 \%)$ vrlo rijetko koristio bilo kakve geste ili ih uopće nije koristio (vidi sliku 1). Informativne geste (primjerice, spontano pokazivanje četiri prsta kada se komentira da nečega ima četiri komada) javile su se nesustavno i prilično oskudno.

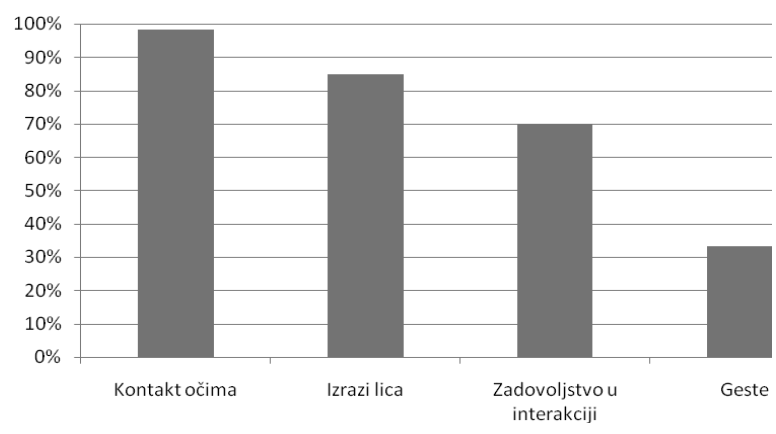

Slika 1. Postotak sudionika koji su postigli potpuno očekivan rezultat (kod 0) na pojedinim varijablama neverbalne komunikacije.

Može se zaključiti da uporaba gesta u djece ovisi i o stupnju i vrsti okolinskih poticaja (Colletta i sur., 2015). U ovom istraživanju je uočeno da su djeca češće koristila geste u onim zadacima u kojima ih je ispitivač više poticao na to. Jednako tako, uporaba gesta se povećava još i u školskoj dobi (Alamillo i sur., 2013), te je moguće da bi djeca školske dobi pokazala veću količinu spontane uporabe gesta, što je važan podatak, budući da se modul 3 protokola ADOS-2 (koji je primijenjen u ovom istraživanju) koristi i u procjeni djece školske dobi.

$\mathrm{Na}$ temelju rezultata deskriptivne statistike može se zaključiti da se prosječan rezultat $(\mathrm{M}=0,87)$ koji su djeca postigla kreće prema pomalo atipičnom ponašanju (kodirano $\mathrm{s} 1$ ), a standardna devijacija $(\mathrm{SD}=0,71)$ potvrđuje raspršenost rezultata, što nam govori da postoji velika neujednačenost rezultata na ovoj varijabli.

Niska pojavnost spontane uporabe gesta (ne gestikulacija!) u djece u našem uzorku može ukazivati na to da govornici hrvatskog jezika u manjoj mjeri koriste geste negoli govornici engleskog jezika. Nažalost, koliko je autorima poznato, nisu provedena istraživanja koja bi poduprijela tu tezu. No, istraživanja jasno ukazuju da neke kulture i jezici imaju tendenciju veće ili manje uporabe gesta u komunikaciji, ali i da se uporaba gesta $u$ istih govornika čak mijenja ovisno o tome kojim jezikom komuniciraju (So, 2010). Istraživanje So (2010) ukazuje da bi stanovnici Sjedinjenih Američkih Država mogli pripadati kulturi koja koristi veću količinu i reprezentacijskih i nereprezentacijskih gesta, te možemo pretpostaviti da su vjerojatno i kriteriji koji se navode u protokolu ADOS-2 proizvod takve kulture komunikacije.

\section{Obilježja pragmatike}

$\mathrm{Na}$ varijablama koje ispituju pragmatiku (učestalost davanja i traženja informacije, pragmatički aspekti opisivanja događaja, te obilježja razgovora) sudionici su, globalno, postigli rezultate koji izlaze iz granica ponašanja koja se, prema protokolu ADOS-2, smatraju urednima ili očekivanima. Najviše odstupanja uočeno je u učestalosti traženja informacija (tablica 5). Samo 15\% djece ostvarilo je kod 0 (uredan rezultat; postavljanje pitanja ispitivaču o njegovim mislima, osjećajima ili doživljajima nekoliko puta tijekom ispitivanja), dok je najveći postotak djece (53\%) ostvario kôd 2 (koji ukazuje na izrazito odstupanje od očekivanja), što znači da su primjereno odgovarali na ispitivačeve komentare o vlastitim mislima, osjećajima ili doživljajima, ali se nisu spontano raspitivali o njima. Aritmetička sredina pokazala je prosječan rezultat $\mathrm{M}=1,38$ koji globalno ukazuje na atipično ponašanje djece (tablica 5). Moguće je da ispitivač nije davao dovoljno jasne promptove djetetu, ili nije davao dovoljno vremena da djeca odreagiraju na njih, ili je to rezultat toga što su djeca bila izdvojena iz grupe, s njima nepoznatim ispitivačem, kojeg su doživljavala kao superiorniju osobu koja „diktira“ pravila komunikacije i odnosa. Vjerujemo da su ovakvi rezultati koji ukazuju na nisku inicijativu djece da traže informacije od nepoznate osobe odraz kulture u kojoj se očekuje da djeca uglavnom odgovaraju na pitanja nepoznatoj osobi, a da ne preuzimaju inicijativu niti ne traže osobne podatke od nepoznatih osoba. Sveukupno je iz literature poznato da američka kultura potiče i cijeni asertivnost (Niikura, 1999), te je doživljava kao komunikacijsku kompetentnost (Singhal i 
Nagao, 1993). Vrlo vjerojatno iz tog razloga autori protokola ADOS-2 očekuju da će djeca u nekoliko navrata pitati ispitivača za njegove misli, osjećaje ili doživljaje, te spontano nuditi informacije o vlastitim osjećajima, mislima ili iskustvima.

U razvoju pragmatike postoje individualne razlike među djecom, ali razlike postoje i unutar samog djeteta kada ono komunicira u različitim situacijama s različitim osobama u različitom vremenskom razmaku (Nelson, 1981). Pretpostavka je da se, kulturalno i odgojno, hrvatsku djecu ne potiče na traženje osobnih informacija od nepoznatih odraslih osoba, posebice u situaciji koja nalikuje na ispitivanje. Autori su primijetili da nerijetko majke djeci prije ispitivanja daju uputu „Budi dobar i slušaj tetu!“”, implicirajući da će „teta“" (ispitivač) biti dominantna u komunikaciji, te da se od djeteta očekuje submisivna uloga.

Na slici 2 vidljiv je postotak djece koja su na različitim varijablama pragmatike postigla uredan (,očekivani“) rezultat (kod 0). Vidljivo je da su ponašanja hrvatske djece bila najviše usklađena $\mathrm{s}$ očekivanjima u opisivanju događaja, zatim u spontanom davanju novih informacija, zatim razgovoru i na kraju, u najmanjoj mjeri, u traženju informacija.

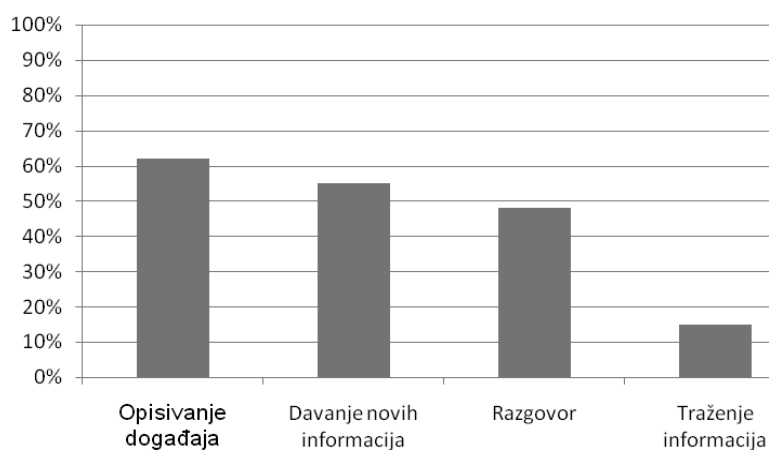

Slika 2. Postotak sudionika koji su postigli potpuno uredan rezultat (kod 0) na različitim varijablama pragmatike.
Kad se jasnije pogledaju kodovi za navedena ponašanja, vidi se da je u njima ,sakrivena“ razina inicijative koja se očekuje od djeteta u komunikaciji s odraslom osobom, za koju vjerujemo da je kulturalno određena. Primjerice, u obilježjima opisivanja događaja, uz razumljivost opisa, vrednuje se i u kojoj mjeri dijete spontano opisuje događaje (primjerice, je li dijete trebalo zamoliti da opiše događaj ili je ono to učinilo spontano). Jednako tako, u obilježjima razgovora se također očekuje da dijete dodatno, mimo odgovora na ispitivačeva pitanja, spontano komentira ispitivačeve iskaze.

Zaključno, ovi rezultati ukazuju na činjenicu da su obilježja uporabe jezika (pragmatike) u velikoj mjeri kulturalno određena, te se „norme“ tipične uporabe jezika i prikladne količine inicijative u komunikaciji usvajaju unutar pojedinog kulturalnog konteksta i socijalne sredine. Iz tog razloga je važno u kliničkoj procjeni obilježja pragmatike imati na umu moguće kulturalne različitosti.

\section{Koordinacija verbalne i neverbalne komunikacije}

Varijabla koja procjenjuje koordiniranost verbalne i neverbalne komunikacije uzeta je kao sumirajuća varijabla verbalnih i neverbalnih varijabli. Ova varijabla kodira stupanj do kojeg sudionikovu verbalnu komunikaciju prate fine promjene u pogledu, izrazima lica i gestama. Frekvencija rezultata pokazuje da je najveći postotak djece ( $70 \%$ ) postigao kod 0 što znači da, kada govore, pokazuju i socijalno prikladne promjene pogleda, izraza lica i uporabe geste. Manji postotak djece $(23,3 \%)$ postigao je kod 1 što znači da su nešto rjeđe koristila geste, pogled i izraze lica ili su u komunikaciji upotrebljavala gotovo isključivo samo jedan modalitet (primjerice, učestala upotreba pogleda, ali ograničena uporaba gesta ili izraza lica), a $6,7 \%$ djece je govor u maloj mjeri povezivalo $\mathrm{s}$ neverbalnom komunikacijom (tablica 6).

Tablica 5. Frekvencija i postotak raspodjele rezultata na varijablama pragmatike.

\begin{tabular}{|c|c|c|c|c|c|c|c|c|}
\hline \multirow[t]{3}{*}{ Naziv varijable } & \multicolumn{6}{|c|}{ Kodovi } & \multirow[t]{3}{*}{$\mathbf{M}$} & \multirow[t]{3}{*}{ SD } \\
\hline & \multicolumn{3}{|c|}{$\mathbf{N}$} & \multicolumn{3}{|c|}{ Postotak (\%) } & & \\
\hline & $\mathbf{0}$ & 1 & 2 & $\mathbf{0}$ & 1 & 2 & & \\
\hline Davanje novih informacija & 33 & 21 & 6 & 55 & 35 & 10 & 0,55 & 0,68 \\
\hline Traženje informacija & 9 & 19 & 32 & 15 & 32 & 53 & 1,38 & 0,74 \\
\hline Opisivanje događaja & 37 & 18 & 5 & 62 & 30 & 8 & 0,47 & 0,65 \\
\hline Razgovor & 29 & 24 & 7 & 48 & 40 & 12 & 0,63 & 0,69 \\
\hline
\end{tabular}


Tablica 6. Frekvencija i postotak raspodjele rezultata varijabli jezične proizvodnje i neverbalne komunikacije.

\begin{tabular}{|c|c|c|c|c|c|c|c|c|}
\hline \multirow[t]{3}{*}{ Naziv varijable } & \multicolumn{6}{|c|}{ Kodovi } & \multirow[t]{3}{*}{$\mathbf{M}$} & \multirow[t]{3}{*}{ SD } \\
\hline & \multicolumn{3}{|c|}{$\mathbf{N}$} & \multicolumn{3}{|c|}{ Postotak (\%) } & & \\
\hline & $\mathbf{0}$ & 1 & 2 & $\mathbf{0}$ & 1 & 2 & & \\
\hline Jezična proizvodnja i neverbalna komunikacija & 42 & 14 & 4 & 70 & 23,3 & 6,7 & 0,37 & 0,610 \\
\hline
\end{tabular}

Osnovni parametri deskriptivne statistike pokazuju da su djeca postigla prosječni rezultat $\mathrm{M}=0,37$, koji odgovara urednim rasponima. Pogledamo li vrijednost standardne devijacije $(\mathrm{SD}=0,61)$ ove varijable možemo zaključiti da i u ovom slučaju ona premašuje vrijednost aritmetičke sredine (tablica 6). Vjerujemo da pomalo povećani postotak djece koja su na ovoj varijabli postigla kod 1 može biti posljedica snižene razine spontane uporabe gesta koja je već ranije evidentirana na varijabli neverbalne komunikacije.

\section{Usporedba ponašanja u području verbalne komunikacije, neverbalne komunikacije i pragmatike}

Sveukupno je iz dosad iznesenih podataka vidljivo da su hrvatska djeca predškolske dobi pokazala relativno očekivane (,uredne“) rezultate u obilježjima verbalne komunikacije (obilježja jezične proizvodnje i govora), dok su, istovremeno, pokazala blago odstupajuća ponašanja u obilježjima neverbalne komunikacije, te još značajnija odstupanja u obilježjima pragmatike, u odnosu na očekivanja autora protokola ADOS-2. Kada se sagleda ukupna količina svih dodijeljenih kodova u ove tri skupine varijabli (slika 3), vidljivo je da tek $45 \%$ kodova u domeni pragmatike odgovaraju „urednim“ očekivanjima, $\mathrm{tj}$. da većina ostvarenih kodova odgovara blažem ili težem odstupanju od očekivanja.

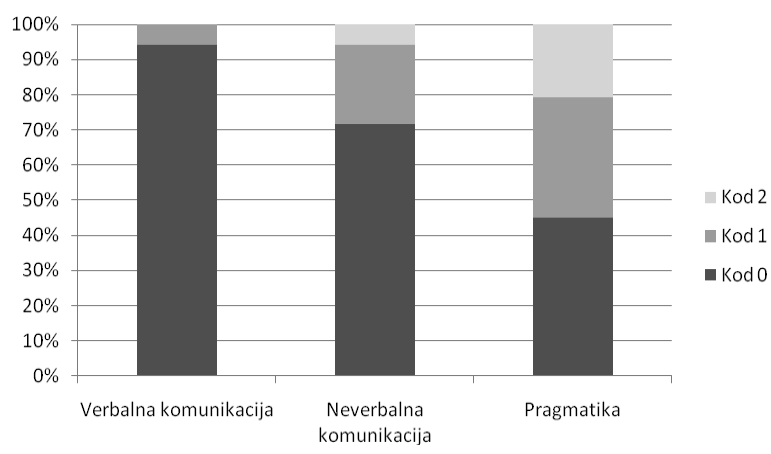

Slika 3. Sveukupni odnosi postignutih kodova 0, $1 i$ 2 na svim varijablama verbalne komunikacije, neverbalne komunikacije i pragmatike.
Ovi podaci ukazuju na potrebu dodatnog preispitivanja mogućih kulturnih razlika u obilježjima neverbalne komunikacije i, nadasve, pragmatike. Količina „odstupajućih“ ponašanja hrvatske djece u području pragmatike ozbiljno narušava dijagnostičku valjanost navedenih varijabli.

Prilikom razmatranja rezultata ovog istraživanja važno je razmotriti neka njegova metodološka ograničenja. Uzorak sudionika bio je relativno malen i prigodan te je moguće da bi obrazac rezultata mogao biti drukčiji da je $u$ istraživanju sudjelovao veći reprezentativni uzorak djece. Nadalje, budući da su se ispitivala obilježja verbalne komunikacije, neverbalne komunikacije i pragmatike hrvatske djece predškolske dobi u radu je možda prisutan problem samo-selekcije sudionika, odnosno moguće je da su pristanak za sudjelovanje dali roditelji koji smatraju da je njihovo dijete kompetentno $\mathrm{u}$ ispitivanim varijablama. Ovo istraživanje, kao i većina sličnih istraživanja provedeno je s djecom iz obitelji srednjeg i višeg socijalnog statusa te $\mathrm{s}$ djecom roditelja srednjeg i višeg stupnja obrazovanja, što dovodi do pitanja koliko je opravdano uopćavati rezultate ovog istraživanja na svu djecu.

\section{ZAKLJUČAK}

Djeca predškolske dobi komuniciraju obilno, i verbalno i neverbalno. Verbalnu komunikaciju karakterizira široki rječnik, složene gramatički točne rečenice, te uglavnom precizno artikulirani glasovi. I dok veći broj istraživanja opisuje obilježja neverbalne komunikacije djece rane dobi (posebice prije pojave jezika ili u ranom razdoblju verbalne komunikacije), obilježja neverbalne komunikacije i pragmatike djece predškolske dobi su prilično neistražena, posebice u različitim kulturama.

Cilj ovog rada bio je ispitati obilježja verbalne i neverbalne komunikacije hrvatske djece predškolske dobi urednog razvoja, te ih sagledati na način kako to čini naširoko korišteni Opservacijski pro- 
tokol za dijagnostiku autizma (Autism Diagnostic Observation Schedule; ADOS-2; Lord i sur., 2012). Rezultati su pokazali da postoje velike individualne razlike među djecom u obilježjima neverbalne komunikacije i pragmatike, ali i da hrvatska djeca pokazuju bitno izmijenjena obilježja pragmatike od onih koje „urednima“ smatraju autori protokola ADOS-2. U pragmatici, djeca pokazuju najviše različitosti, i to prvenstveno u traženju informacija, što znači da su tijekom ispitivanja primjereno odgovarala na ispitivačeve komentare o vlastitim mislima osjećajima ili doživljajima, ali se nisu spontano raspitivala o njima. U području neverbalne komunikacije najviše razlika je bilo u korištenju gesti. Djeca su koristila geste kada se to od njih tražilo ili kada ih se navodilo da ih koriste. Sveukupno se čini da protokol ADOS-2, koji je nastao pod utjecajem američke kulture i normi komunikacije, očekuje pojavu veće inicijative u komunikacije, kao i obilnije korištenje gesta.
Ovi podaci ukazuju na potrebu dodatnih istraživanja koja bi dala jasnije normativne podatke o razvoju pojedinih aspekata neverbalne komunikacije i pragmatike u djece i osoba različite dobi i različitih kultura. Posljedično, i sam dijagnostički instrumentarij bi bilo uputno, osim jezične prilagodbe, prilagoditi i obilježjima komunikacije određene kulture. To je važno za sve mjerne instrumente koje se zasnivaju na procjeni bilo kojeg oblika ponašanja, a posebno za one koji ispituju i kodiraju/boduju obilježja same socijalne komunikacije i na temelju kojih se donose kliničke odluke (tj. dijagnoze). Bez njihove kulturalne prilagodbe, postoji opasnost postavljanja neprimjerenih kriterija za donošenje dijagnostičkih odluka.

\section{ZAHVALA}

Ovaj rad je sufinancirala Hrvatska zaklada za znanost (HRZZ:93743-2014). 


\section{LITERATURA}

Akechi, H., Senju, A., Uibo, H., Kikuchi, Y., Hasegawa, T., Hietanen, J.K. (2013): Attention to eye contact in the West and East: autonomic responses and evaluative ratings. Plos ONE, 8, e59312.

Al-Heizan, M., AlAbdulwahab, S.S., Kachanathu, S., Natho, M. (2015): Sensory processing dysfunction among Sausi children with and without autism. Journal of Physical Therapy Sciences, 27, 1313-1316.

Alamillo, A.R., Colletta, J.M., Guidetti, M. (2013): Gesture and language in narratives and explanations: The effects of age and communicative activity on late multimodal discourse development. Journal of Child Language, 40, 511-538.

Američka psihijatrijska udruga (2014): Dijagnostički i statistički priručnik za duševne poremećaje, peto izdanje. Jastrebarsko: Naklada Slap.

Bates, E., Dale, P.S., Thal, D. (1995): Individual differences and their implications for theories of language development. U Fletcher, P., MacWhineey, B. (ur): Handbook of Child Language (str. 96-151). Oxford: Basil Blackwell.

Caron, K.G., Schaaf, R.C., Benevides, T.W., Gal, E. (2012): Cross-cultural comparison of sensory behaviors in children with autism. American Journal of Occupational Therapy, 66, e77-e80.

Colletta, J.M., Guidetti, M., Caprici, O., Cristilli, C., Demir, O.E., Kunene-Nicolas, R.N., Levine, S. (2015): Effects of age and language on co-speech gesture production: an investigation of French, American and Italian children's narratives. Journal of Child Language, 42, 122-145.

DeWeerdt, S. (2012): Culture: diverse diagnostics. Nature, 491, S18-S19.

DeZarobe, L.R., DeZarobe, Y.R. (2012): Introduction: pragmatics across languages and cultures. Linguistic Insights, $132,9-23$.

Ennis-Cole, D., Durodoye, B.A., Harris, H.L. (2013): The impact of culture on autism diagnosis and treatment. The Family Journal, 21, 279-287.

Huttunen, K.H., Pine, K.J., Thurnham, A.J., Khan, C. (2013): The changing role of gesture in linguistic development: a developmental trajectory and a cross-cultural comparison between British and Finnish children. Journal of Psycholinguistic Research, 42, 81-101.

Jack, R.E., Garrod, O.G.B., Yu, H., Caldara, R., Schyns, P.G. (2012): Facial expressions of emotion are not culturally universal. Proceeding of the National Academy of Sciences of the United States of America, 109, 7241-7244.

Kuvač Kraljević, J., Kologranić Belić, L. (2015). Rani jezični razvoj. U: Kuvač Kraljević, J. (ur.): Priručnik za prepoznavanje i obrazovanje djece s jezičnim teškoćama (str. 24-33). Zagreb: Edukacijsko-rehabilitacijski fakultet.

Lord, C., Luyster, R., Gotham, K., Guthrie, W. (2012): Autism Diagnostic Observation Schedule, second edition (ADOS-2) manual. Torrance, CA: Western Psychological Services.

Magaña, S., Smith, L.E. (2013): The use of the Autism Diagnostic Interview-Revies with a Latino population of adolescents and adults with autism. Journal of Autism and Developmental Disorders, 43, 1098-1105.

Matson, J.L., Worley, J.A., Fodstad, J.C., Chung, K.M., Suh, D., Jhin, H.K., Ben-Itzchak, E., Zachor, D.A., Furniss, F. (2011): A mutinational study examining the cross cultural differences in reported symptoms of autism spectrum disorders: Israel, South Korea, the United Kingdom, and the United States of America. Research in Autism Spectrum Disorders, 5, 1598-1604.

McLaren, M.C. (1998): Interpreting cultural differences: the challenge of intercultural communication. Norfolk: Peter Francis Publishers.

Moran, R.T., Harris, P.R., Moran, S.V. (2007): Managing cultural differences: global leadership strategies for the 21st century. Oxford: Elsevier Butterworth-Heinemann

Nelson, K. (1981): Individual differences in language development: Implication for development and language. Developmental Psychology, 17(2), 170-187. 
Niikura, R. (1999): Assertiveness among Japanese, Malaysian, Filipino and U.S. white-collar workers. The Journal of Social Psychology, 139, 690-698.

Norbury, C.F., Sparks, A. (2013): Difference or disorder? Cultural issues in understanding neurodevelopmental disorders. Developmental Psychology, 49, 45-58.

Perepa, P. (2014): Cultural basis of social „deficits“ in autism spectrum disorders. European Journal of Special Needs Education, 29, 313-326.

Singhal, A. i Nagao, M. (1993): Assertiveness as communication competence: a comparison of the communication styles of American and Japanese students. Asian Journal of Communication, 3, 1-18.

So, W.C. (2010): Cross-cultural transfer in gesture frequency in Chinese-English bilinguals. Language and Cognitive Processes, 25, 1335-1353..

Soto, S., Linas, K., Jacobstein, D., Biel, M., Migdal, T., Anthony, B.J. (2014): A review of cultural adaptations of screening tools for autism spectrum disorders. Autism, 19, 646--661.

Svjetska zdravstvena organizacija (1994): Međunarodna klasifikacija bolesti i srodnih zdravstvenih problema-10. Zagreb: Medicinska naklada.

Zhang, J., Wheeler, J. J., Richley, D. (2006): Cultural validity in assessment instruments for children with autism from a Chinese cultural perspective. International Journal of Special Education, 21, 109-113.

\section{DO TYPICALLY DEVELOPING CROATIAN PRESCHOOL CHILDREN HAVE ,TYPICAL“ COMMUNICATION?}

Abstract: The characteristics of verbal communication, nonverbal communication, and pragmatics are largely determined by the culture and social expectations of a particular society. The evaluation of communication features is important in the diagnostics of numerous developmental disorders, particularly autism spectrum disorder, and in recent years the need for the cultural adaptation of both screening and diagnostics scales for autism spectrum disorder (ASD) is emphasized.

The aim of this study was to investigate the characteristics of verbal communication, nonverbal communication, and pragmatics in Croatian typically developing preschool children (5- and 6-year-olds), and code them according to the American scale Autism Diagnostic Observation Schedule (ADOS-2, module 3).

The results showed that Croatian preschool children show typical features of verbal communication (characteristics of language production and speech), but show some atypical features in non-verbal communication, and, to a large extent, atypical features of pragmatics. The differences are mostly noticed in the amount of spontaneous use of gestures and all pragmatics variables that take into account the amount of initiatives in communication (e.g., spontaneously asking for information or giving information). For example, only 15\% of the children in the sample requested information at a frequency that is expected by code 0 (typical behavior) of ADOS-2.

Although significant individual differences were observed among the children, the amount of "deviating" behavioral characteristics of non-verbal communication and pragmatics emphasizes the need to review the set of codes and adjust criteria in different cultures.

Keywords: verbal communication, nonverbal communication, pragmatics, preschool children, ADOS-2 